\title{
A method for using stationary networks to observe long term trends of on- road emissions factors of primary aerosol from heavy duty vehicles
}

\author{
Helen L. Fitzmaurice ${ }^{1}$, Ronald C. Cohen ${ }^{1,2}$
}

$5 \quad{ }^{1}$ Department of Earth and Planetary Science, University of California Berkeley, Berkeley, 94720, United States

${ }^{1}$ Department of Chemistry, University of California Berkeley, Berkeley, 94720, United States

Correspondence to: Ronald C. Cohen (rccohen@berkeley.edu)

\begin{abstract}
Heavy-duty vehicles (HDV) contribute a significant, but decreasing, fraction of primary aerosol emissions in urban areas. Previous studies have shown spatial heterogeneity in compliance with regulation. Consequently, location-

10 specific emissions factors are necessary to describe primary particulate matter (PM) emissions by HDV. Using near-road observations from the Bay Area Air Quality Management District (BAAQMD) network over the 2009-2020 period in combination with Caltrans measurements of vehicle number and type, we determine primary $\mathrm{PM}_{2.5}$ emission factors from
\end{abstract} HDV on highways in the San Francisco Bay Area. We demonstrate that HDV primary aerosol emission factors derived using this method are in line with observations by other studies, that they decreased a by a factor of $\sim 7$ in the past decade, and that they are still 2-3 times higher than would be expected if all HDV were in compliance with California HDV regulations.

\section{Introduction}

Exposure to aerosols smaller than 2.5 microns in diameter $\left(\mathrm{PM}_{2.5}\right)$ at current ambient levels is estimated to cause 130,000 excess deaths per year in the United States (Tessum, 2019). Epidemiological studies have shown that health and mortality impacts from $\mathrm{PM}_{2.5}$ persist at concentrations of $\mathrm{PM}_{2.5}$ below current National Ambient Air Quality Standards and that small changes in $\mathrm{PM}_{2.5}$ concentration may result in substantial health impacts (Di et al, 2017). Because of the health impacts resulting from small increases in $\mathrm{PM}_{2.5}$, air quality academics, public health researchers, local regulatory agencies, and state governments have come to appreciate the importance of neighborhood scale differences in cumulative exposure to $\mathrm{PM}_{2.5}$ (e.g. CARB, 2018). For example, regulatory agencies in California have begun to shift from a paradigm based primarily on

25 compliance with annual and daily, regional scale air quality metrics to one also focused on mitigation of cumulative exposure, creating local remediation plans based on source apportionment. (BAAQMD, 2019). These source apportionment estimates are created from bottom-up emissions inventories using emissions factors and activity data. Consequently, accurate local emissions factors are vital to understanding and planning neighborhood-scale mitigation strategies.

On-road vehicles, specifically HDV, are a large contributor to aerosol in urban areas, both through direct emissions and through

30 secondary formation in the atmosphere (e.g. Shah, 2018; BAAQMD, 2011). Total emissions can be thought of as the product of emissions factors (EFs) and the activity, where the EFs are expressed in units of grams of aerosol per unit activity (such as grams of aerosol per $\mathrm{kg}$ of fuel burned or per $\mathrm{km}$ travelled). EFs are estimated for on-road activity in a variety of ways including 
scaling based on measurements in a lab setting and/or on-road measurements (See references, Table 1). A summary of on-road studies for primary HDV and passenger vehicle PM EFs over the last 25 years is shown in Figure 1 and Table 1. These studies determined EFs of primary on-road aerosol by comparing ratios of aerosol enhancement (in grams) to $\mathrm{CO}_{2}$ and/or $\mathrm{CO}$ enhancement (as a measure of fuel burned). Measurements included sampling directly in the exhaust of tunnels, and high frequency sensors near or above roads to sample and characterize individual vehicle plumes.

These prior observations show that typical heavy duty, diesel-powered vehicles dominated on-road emissions of primary aerosol in the 1990s and early 2000s. However, in recent years, emissions factors from typical heavy-duty vehicles have been dramatically reduced such that PM EFs of HDVs are now similar to those of light duty vehicles (LDV) and are less than 0.05 $\mathrm{g}$ aerosol/kg fuel burned. Control technologies such as diesel particulate filters and selective catalytic reduction are contributing to these reductions in EFs for HDVs.

While these improvements are seen in the "typical" HDV, previous studies indicate that compliance of HDV with emission technology requirements, and therefore HDV on-road emissions factors, vary by up to an order of magnitude from location to

45 location (Preble, 2018 Bishop, 2015; Haugen, 2018; Haugen, 2019). For example, Bishop (2015) and Haugen (2018, 2019) found emissions factors measured at the Port of Los Angeles were as much as an order of magnitude lower than those measured along a highway in Cottonwood, California during the same season. While the gap between the two sites narrowed from 20132017, the mean emission factors measured in Cottonwood were still 3 times those measured at the Port of Los Angeles in 2017. Similarly, Preble (2018) found that while 100\% of trucks at the Port of Oakland were registered by the state of California as

50 being in compliance with HDV control technology regulations, compliance rates amongst HDV at the Caldecott tunnel (also in Oakland, CA) were below $90 \%$.

These studies highlight that variability in emissions factors as a function of location may affect exposure. They point to the importance of characterizing spatial variation in HDV emissions if we are to understand aggregate emissions from the sector and its localized impacts. To assess the potential for existing data sources to supply the needed information, here we explore 55 the use of regulatory sensor networks (near-highway, hourly $\mathrm{PM}_{2.5}$ and $\mathrm{CO}$ (or $\mathrm{CO}_{2}$ ) measurements), paired with coincident traffic data including LDV and HDV counts, to quantify spatial variation in HDV EFs. Such data is widely available. For example, in the US, there are more than 550 regulatory sites at which $\mathrm{PM}_{2.5}$ and $\mathrm{CO}$ are collocated, some of which have measurements spanning more than a decade (https://www.epa.gov/outdoor-air-quality-data). Of these, 154 are located within $500 \mathrm{~m}$ of a highway. The large number of these sites and their longevity allow for examination of regional and temporal differences in EFs for HDV across the United States. In the future, the approach we outline should be even more widely applicable when dense low-cost sensor networks including aerosol and $\mathrm{CO}$ or $\mathrm{CO}_{2}$ are available as a data source (e.g. Shusterman, 2016, Kim, 2018; Zimmerman, 2018). Because HDV emissions control regulations vary regionally in the US, this method has the potential to shed light on regional differences in HDV EF trends.

We begin by describing a general method for using such data to derive EFs of primary $\mathrm{PM}_{2.5}$ from HDV (Section 2). We then

65 (section 3) test our method by using data from four near-highway sites operated by the Bay Area Air Quality Management 
District (BAAQMD) in the San Francisco Bay Area (Figure 2a) over the period of 2009-2018. In section 4 we discuss the relationship of these findings to measures of exposure.

\section{Data and Methods}

\subsection{Aerosol and CO Measurements}

We use $1 \mathrm{hr}$ averaged observations from 18 of the BAAQMD regulatory sites which measure $\mathrm{PM}_{2.5}$ using Beta Attenuation Monitors and CO using the Thermo Scientific TE48i IR sensor. Some sites have been in operation since 2009, while others have been brought online as recently as 2018 , or were operational for only a few years during this time period. Data was retrieved from https://aqs.epa.gov/aqsweb/documents/data_api.html. Site locations are summarized in Figure 2.

\subsection{Meteorology}

Boundary layer height and wind speed and direction are taken from the European Center for Meteorology and Weather Forecasting (ECMWF) ERA5 reanalysis, (https://cds.climate.copernicus.eu/cdsapp\#!/dataset/reanalysis-era5-land?tab=form). Typical diel cycles for boundary layer height and total windspeed are shown in figure S6.

80

\subsection{Traffic Data}

Total vehicle flow and the percent of vehicles that are HDV are taken from the Caltrans' Performance Measurement System (PeMS) database (http://pems.dot.ca.gov), which records these parameters at over 1800 locations on highways in the Bay Area. We include all BAAQMD sites that are within 500 meters of one major highway and use traffic count data from the PeMS

85 measurement site closest to each air quality site. In cases of missing PeMS data, data was filled in with the median value associated with that parameter for a particular site in a particular year, or if not possible, retrieved from the second or third nearest sites. More details about the PeMS data are presented in FigS1, TableS1, and FigS2.

\subsection{Derivation of $\mathrm{EF}_{\mathrm{PM}(\mathrm{HDV})}$}

Our derivation of HDV EFs assumes that the relationship between PM and CO, as observed near-road, can be scaled so that it

90 represents PM per unit of fuel burned by HDVs (Equation 1):

$$
E F_{P M(H D V)}=\gamma \frac{P M_{H D V}}{C O_{\text {fleet }}} \frac{g C O_{\text {fleet }}}{\mathrm{kg} \text { fuel }_{\text {fleet }}} \frac{\mathrm{kg} \text { fuel }_{\text {fleet }}}{\mathrm{kg} \mathrm{fuel}, H D V},(1)
$$

In this equation, $\gamma=0.0008$, and is the ideal gas law conversion factor, from $\left(\mu \mathrm{g} / \mathrm{m}^{3} \mathrm{ppm}^{-1} \mathrm{CO}\right)$ to $(g P M / g C O)$. Below, we describe the steps used to calculate each term in equation (1).

The first term $\frac{P M_{H D V}}{C O_{\text {fleet }}}$ in the equation is derived from observations as the slope of a linear fit of near-road $\mathrm{PM}_{2.5}$ (assumed 95 to be primarily emitted by HDV) and near-road CO (assumed to be emitted by both HDV and LDV). This term is derived by 
(1) isolating local enhancements of $\mathrm{PM}_{2.5}$ and $\mathrm{CO}$, (2) isolating roadway enhancements by use of temporal filters and (3) fitting resulting roadway enhancements of $\mathrm{PM}_{2.5}$ and $\mathrm{CO}$ to a line, as detailed below.

(1) To isolate local enhancements from total signal $\mathrm{PM}_{2.5}$ and $\mathrm{CO}$, we first leverage the entire BAAQMD network to derive an hourly regional signal for each species. The regional signal is defined as the $10^{\text {th }}$ percentile of the data across all 22 BAAQMD sites within a five-hour window of that hour (Figure 2b). This regional signal is assumed to be composed of background $\mathrm{PM} / \mathrm{CO}$ transported to the region from elsewhere as well as region-wide sources of secondary aerosol/CO. We the find the enhancement by local primary emissions by subtracting the regional signal from total signal at each site.

(2) We isolate primary emissions from on-road sources by considering only the morning commute times and only during fall and winter. These are times coinciding with relatively high traffic emissions and too early in the day for significant accumulation of new secondary aerosol. We find the 6-8 am period represents the optimal overlap of low boundary layer height (Figure S6) and HDV emissions (Figure S2). To avoid observations of stagnant air, we only include observations with wind speed above $0.5 \mathrm{~m} / \mathrm{s}$. We also exclude known fire events. The result of these first two steps are enhancements, $\Delta \mathrm{PM}_{2.5}$ and $\Delta \mathrm{CO}$ above background.

(3) The slope of a linear fit of the median $\Delta \mathrm{PM}_{2.5}$ in bins of $\Delta \mathrm{CO}$ (see figure 3) is defined as the "enhancement ratio," $\alpha$, in units of $\mu \mathrm{g} / \mathrm{m}^{3} \mathrm{ppm}^{-1}$-CO. Using the lengthy dataset, we are able to derive $\alpha$ for different percentages of HDV in the vehicle fleet on the road. There are some high $\Delta \mathrm{PM}_{2.5}$ values uncorrelated with $\Delta \mathrm{CO}$ as shown in Figure 3. In all cases, these points show little to no $\mathrm{NO}_{\mathrm{x}}$ enhancement and thus are characteristic of a source that is not HDV. We make the assumption that LDV PM EFs are negligible and on-road primary emissions of aerosol are solely from HDV, implying that $\alpha$ is equivalent to the term $\frac{P M_{H D V}}{C O_{\text {fleet }}}$. This assumption is sound at the beginning of our period (2010s) of interest, because reported values of $\mathrm{EF}_{\mathrm{PM}(\mathrm{HDV})}$ were 2-3 orders of magnitude higher than $\mathrm{EF}_{\mathrm{PM}(\mathrm{LDV})}$ at that time (Fig 1). More recently, as $\mathrm{EF}_{\mathrm{PM}(\mathrm{HDV})}$ has decreased, this is less clear, especially without on-road estimates of $\mathrm{EF}_{\mathrm{PM}(\mathrm{LDV})}$. To understand the impact of LDV PM emissions on our findings, we establish an upper bound for $\mathrm{EF}_{\mathrm{PM}(\mathrm{LDV})}$ to be $0.002 \mathrm{~g} \mathrm{PM} / \mathrm{kg}$ fuel by insisting that all $\mathrm{EF}_{\mathrm{PM}(\mathrm{HDV})}>0$ and find the impact of LDV PM on the longterm trends of $\mathrm{EF}_{\mathrm{PM}(\mathrm{HDV})}$ to be minimal (Test S9, FigS9).

The term $\frac{\mathrm{gCO}_{\text {fleet }}}{\mathrm{kg} \text { fuel, fleet }}$ is the fleet EF for CO. We use truck percentage and CO emission factors from EMFAC2017 model and fuel efficiency estimates to calculate this term as follows: $E F_{C O, f l e e t}=\frac{E F_{C O(H D V)} t_{H D V}+E F_{C O(L D V)}(1-t) E_{L D V}}{t E_{H D V}+(1-t) E_{L D V}}$, (2) where $t$ is the HDV fraction and $\mathrm{E}$ is fuel efficiency (miles / gallon). $\mathrm{EF}_{\mathrm{CO}}$ for both LDV and HDV is defined for each time period using the EMFAC2017 model.

125 Finally, $\frac{\mathrm{kg} \text { fuel }_{\text {fleet }}}{\mathrm{kg} \text { fuel,HDV }}$ is the ratio of fuel burned by the total vehicle fleet to that burned by HDV alone. We find this ratio to be $\frac{t E_{H D V}+(1-t) E_{L D V}}{t E_{H D V}}$. 
Because, at a given site, we expect $\frac{P M_{H D V}}{C O_{\text {fleet }}}$ (but not $\mathrm{EF}_{\mathrm{PM}(\mathrm{HDV})}$ ) to vary linearly with $\mathrm{HDV}$ fraction, we bin data by HDV fraction in increments of 0.02 , use the process above to calculate $\mathrm{EF}_{\mathrm{PM}(\mathrm{HDV})}$ for each bin. We use the $95^{\text {th }}$ percent confidence intervals to represent uncertainty in $\mathrm{EF}_{\mathrm{PM}(\mathrm{HDV})}$ for each bin, and finally, calculate $\mathrm{EF}_{\mathrm{PM}(\mathrm{HDV})}$ for each site during a particular time period using the average of the, weighted by uncertainty in $\mathrm{EF}_{\mathrm{PM}(\mathrm{HDV})}$ for each bin.

\section{HDV Emissions Factors from Primary Aerosols in SF Bay Area: 2009-2018}

The result of this procedure is HDV EFs at four near-highway BAAQMD sties (Redwood City, Berkeley Marina, San Rafael, Pleasanton) during the time periods: 2009-2011, 2012-2015, 2016-2018. (Figure 4.) HDV EFs decrease over the decade (Figure 1, Figure 4), amounting to a roughly seven fold reduction. Site to site differences in HDV EFs remain substantial. For example, during the 2018-2020 period, we see a range of more than a factor of 10 with a minimum of $0.02+/ 0.10 \mathrm{~g} \mathrm{PM} / \mathrm{kg}$ fuel to a maximum of $0.38+/ 0.07 \mathrm{~g} \mathrm{PM} / \mathrm{kg}$ fuel. Both the temporal decrease and the site to site differences are similar to prior reports derived using other approaches to data collection and interpretation (e.g. Haugen et al. 2017, 2018).

By 2020, California law required that all HDV models from the years 1995-2003 replace their engines with 2010 or newer models, and that all HDV model year 1994 or newer use diesel particulate filters (DPF) (California Code of Regulaitons). Assuming that the fleetwide average EF for models with 2010 or newer engines using DPF is $0.03 \mathrm{~g}$ PM / $\mathrm{kg}$ fuel as observed by Haugen (2018), we can use fuel usage by HDV model year in 2020 as well as emissions factors for vehicles older than 1994 estimated by the Emissions FACtor Model (EMFAC2017) to estimate a fleetwide average. Thus a fleetwide average should have an EF of 0.03-.06 g PM / kg fuel if the trucks were fully compliant in 2018-2020. We observe an average EF of $0.11 \mathrm{~g}$ $\mathrm{PM} / \mathrm{kg}$ fuel, for 2018-2020, more than 2-3 times larger than expected for an HDV fleet compliant with current regulations. Possible explanations for this discrepancy include exemptions from truck regulations, under which certain classes of HDV travelling less than 15,000 miles per year are eligible for exemptions, meaning locally travelling HDV may have higher emissions factors than those travelling long distances (CARB, 2018), the fact that HDV registered in other states are not typically subject to CA regulations unless they enter specific areas, such as ports and failure of or tampering with installed

\section{0 equipment.}

We also observe site to site variation in emission factors. For example, while emission factors at both Redwood City and Santa Rosa drop throughout the time period observed and each experiences a sharp drop between different two time periods, that sharp drop occurs earlier (2009-2011 to 2012-2014) at RWC than at SR (2012-2014 to 2015-2017), suggesting a difference in timing of compliance to control technologies at each place. Furthermore, in the 2018-2020 period, we see a wide range in emission factors, likely indicating a range in compliance.

We found reliable results using this procedure at 4 near-road locations that are well separated from other activity. However, at some at other locations apparent large emissions are observed, that we believe to be unphysical. For example, the $\mathrm{EF}_{\mathrm{HDV}}$ calculated for Laney College in the 2015-2017 and 2018-2020 periods is significantly higher than EF $\mathrm{HDV}$ observed at the four 
sites we deem reliably far from other sources. While it is possible that HDV on the highway near Laney College, are unusually high emitters, it is more likely that emissions from a nearby parking lot are responsible for the high inferred EFs. (See Text S7 and Fig S7.) Slow moving LDV could be an important influence on local emissions, a factor that should be assessed more thoroughly.

\section{4 - Primary $\mathrm{PM}_{2.5}$ exposure}

To understand exposure from HDV $\mathrm{PM}_{2.5}$, we calculate both a region-wide addition to aerosol burden by HDV emissions and an enhancement as a function of distance from a highway. Assuming steady-state, a box of $100 \mathrm{~km}$ in length, $160 \mathrm{~m}$ in height, and a wind-speed of $1.2 \mathrm{~m} / \mathrm{s}$ (Figure S6), and using fuel sales data (Moua, 2020) to estimate total HDV fuel used, we estimate a maximum region-wide enhancement on the order of $0.2 \mu \mathrm{g} / \mathrm{m}^{3}$ on a typical day in the 2018-2020 period, compared to an enhancement of $1.3 \mu \mathrm{g} / \mathrm{m}^{3}$ during the 2009-2011 period (Figure S7). Decreases in emissions factors over the past decade are countered by the increase in diesel fuel usage (70\%) (Moua, 2020) such that there has been only a small change in typical regional exposure to primary PM from HDV. (See figure S7a for diel cycle of modeled region-wide enhancement.) While an enhancement of $0.2 \mu \mathrm{g} / \mathrm{m}^{3}$ is small in comparison to average ambient $\mathrm{PM}_{2.5}\left(8.3-14.4 \mu \mathrm{g} / \mathrm{m}^{3}\right.$ for all BAAQMD sites in 2018), it is sizeable in comparison to average ambient BC (.4-1 $\mu \mathrm{g} / \mathrm{m}^{3}$ for all BAAQMD sites in 2018).

175 To gauge near roadway exposure, PM enhancement from HDV was calculated as a function of distance from a highway, modeled treating emissions from the highway as a gaussian plume flowing perpendicular to a line source. Assuming both highway and point of measurement at ground level, the simplified gaussian plume dispersion for a line source yields:

$P M_{\text {enh }}=\frac{2 \lambda}{\sqrt{2 \pi} u \sigma_{z}}(3)$

where $\lambda$ is an emissions rate per unit highway length, $\mathrm{u}$ is wind speed, and $\sigma_{z}$ is a dispersion parameter. For a typical daytime HDV flow rate of 500 vehicles per hour (Figure S2) and windspeed of $1.2 \mathrm{~m} / \mathrm{s}$ (Figure S6), we calculate PM enhancement as a function of perpendicular distance downwind of a highway. For unstable atmospheric conditions $\left(\sigma_{z}=\frac{0.102 x}{\left(1+\frac{x}{927}\right)^{-1.92}}\right)$, enhancements drop to values below $1 \mu \mathrm{g} / \mathrm{m}^{3}$ in the first $200 \mathrm{~m}$. For stable conditions $\left(\sigma_{z}=\frac{0.022 x}{\left(1+\frac{x}{1170}\right)^{0.7}}\right)$, such as those typical of early morning, enhancements of $\sim 0.8 \mu \mathrm{g} / \mathrm{m}^{3}$ are predicted up to a kilometer away.

\section{Conclusions}

185 We find that HDV EFs in the SF Bay Area have decreased by about a factor of seven over the last decade, consistent with trends reported in other analyses in this region and Los Angeles. We find spatial variation of HDV EFs remains large indicating a wide range in the application of retrofit technologies and possible that vehicles legally exempt from compliance with the current standards are a significant portion of those on the road at the sampling sites. 


\section{References}

190 Ban-Weiss, G.A., McLaughlin, J.P., Harley, R.A., Lunden, M.M., Kirchstetter, T.W., Kean, A.J., Strawa, A.W., Stevenson, E.D. and Kendall, G.R., 2008. Long-term changes in emissions of nitrogen oxides and particulate matter from on-road gasoline and diesel vehicles. Atmospheric Environment, 42(2), pp.220-232., https://doi.org/10.1016/j.atmosenv.2007.09.049

Ban-Weiss, G.A., Lunden, M.M., Kirchstetter, T.W. and Harley, R.A., 2010. Size-resolved particle number and volume emission factors for on-road gasoline and diesel motor vehicles. Journal of Aerosol Science, 41(1), pp.5-12., https://doi.org/10.1016/j.jaerosci.2009.08.001

Bishop, G.A., Hottor-Raguindin, R., Stedman, D.H., McClintock, P., Theobald, E., Johnson, J.D., Lee, D.W., Zietsman, J. and Misra, C., 2015. On-road heavy-duty vehicle emissions monitoring system. Environmental science \& technology, 49(3), pp.1639-1645., https://doi.org/10.1021/es505534e

Bishop, G.A., 2019. Three decades of on-road mobile source emissions reductions in South Los Angeles. Journal of the Air \& Waste Management Association, 69(8), pp.967-976., https://doi.org/10.1080/10962247.2019.1611677

205 Fanai, A.K, Claire, S.J., Dinh, T.M., Nguyen, Scultz, S.A. Bay Area Emissions Inventory Report: Criteria Air Pollutants: Base Year 2011, Bay Area Air Quality Management District. 2014

Martien, P., Fanai, A.K, Claire, S.J., Dinh, T.M., Nguyen, Scultz, S.A. Base Year 2011 Emission Inventory: Source Category Methodologies. Bay Area Air Quality Management District. 2014

210 California Air Resources Board. Community Air Protection Blueprint. 2018. Retrieved from: https://ww2.arb.ca.gov/sites/default/files/2020-03/final_community_air_protection_blueprint_october_2018_acc.pdf

California Air Resources Board. (2018) Truck and Bus Regulation - Low Mileage Construction Truck Phase-in Option. Retrieved from: https://ww3.arb.ca.gov/msprog/onrdiesel/documents/faqconstructiontrucks.pdf

Title 13, Section 2025, California Code of Regulations Regulation to Reduce Emissions of Diesel Particulate Matter, Oxides of Nitrogen and Other Criteria Pollutants from In-Use Heavy-Duty Diesel-Fueled Vehicles.

Caubel, J.J., Cados, T.E., Preble, C.V. and Kirchstetter, T.W., 2019. A distributed network of 100 black carbon sensors for 220100 days of air quality monitoring in West Oakland, California. Environmental science \& technology, 53(13), pp.75647573., https://doi.org/10.1021/acs.est.9b00282

Choi, W., Winer, A.M. and Paulson, S.E., 2014. Factors controlling pollutant plume length downwind of major roadways in nocturnal surface inversions. Atmospheric Chemistry and Physics, 14(13), pp.6925-6940., https://doi.org/10.5194/acp-14$\underline{6925-2014}$

Dallmann, T.R., Harley, R.A. and Kirchstetter, T.W., 2011. Effects of diesel particle filter retrofits and accelerated fleet turnover on drayage truck emissions at the Port of Oakland. Environmental science \& technology, 45(24), pp.10773-10779., https://doi.org/10.1021/es202609q

Dallmann, T.R., Kirchstetter, T.W., DeMartini, S.J. and Harley, R.A., 2013. Quantifying on-road emissions from gasolinepowered motor vehicles: Accounting for the presence of medium-and heavy-duty diesel trucks. Environmental science \& technology, 47(23), pp.13873-13881., https://doi.org/10.1021/es402875u

235 Dallmann, T.R., DeMartini, S.J., Kirchstetter, T.W., Herndon, S.C., Onasch, T.B., Wood, E.C. and Harley, R.A., 2012. Onroad measurement of gas and particle phase pollutant emission factors for individual heavy-duty diesel trucks. Environmental science \& technology, 46(15), pp.8511-8518., https://doi.org/10.1021/es301936c 
Dallmann, T.R., Onasch, T.B., Kirchstetter, T.W., Worton, D.R., Fortner, E.C., Herndon, S.C., Wood, E.C., Franklin, J.P., gasoline and diesel vehicles using a soot particle aerosol mass spectrometer. Atmospheric Chemistry and Physics, 14(14), pp.7585-7599., https://doi.org/10.5194/acp-14-7585-2014

Di, Q., Wang, Y., Zanobetti, A., Wang, Y., Koutrakis, P., Choirat, C., Dominici, F. and Schwartz, J.D., 2017. Air pollution and mortality in the Medicare population. New England Journal of Medicine, 376(26), pp.2513-2522., https://doi:10.1056/NEJMoa1702747

Geller, M.D., Sardar, S.B., Phuleria, H., Fine, P.M. and Sioutas, C., 2005. Measurements of particle number and mass concentrations and size distributions in a tunnel environment. Environmental Science \& Technology, 39(22), pp.86538663., https://doi.org/10.1021/es050360s

Haugen, M.J. and Bishop, G.A., 2018. Long-Term Fuel-Specific NO x and Particle Emission Trends for In-Use Heavy-Duty Vehicles in California. Environmental science \& technology, 52(10), pp.6070-6076., https://doi.org/10.1021/acs.est.8b00621

Haugen, M.J. and Bishop, G.A., 2017. Repeat fuel specific emission measurements on two California heavy-duty truck fleets. Environmental science \& technology, 51(7), pp.4100-4107., https://doi.org/10.1021/acs.est.6b06172

Kirchstetter, T.W., Harley, R.A., Kreisberg, N.M., Stolzenburg, M.R. and Hering, S.V., 1999. On-road measurement of fine

255 particle and nitrogen oxide emissions from light-and heavy-duty motor vehicles. Atmospheric Environment, 33(18), pp.29552968., https://doi.org/10.1016/S1352-2310(99)00089-8

Li, X., Dallmann, T.R., May, A.A., Stanier, C.O., Grieshop, A.P., Lipsky, E.M., Robinson, A.L. and Presto, A.A., 2018. Size distribution of vehicle emitted primary particles measured in a traffic tunnel. Atmospheric Environment, 191, pp.9-18., https://doi.org/10.1016/j.atmosenv.2018.07.052

Moua, F., 2018 California Annual Fuel Outlet Report Results (CEC-A15), Energy Assessments Division, California Energy Comission, 2020. retrieved from: https://ww2.energy.ca.gov/almanac/transportation_data/gasoline/piira_retail_survey.html

265 BAAQMD, West Oakland Environmental Indicators Project. 2019. Owning Our Air: the West Oakland Community Action Plan_Volume 1: the Plan. https://www.baaqmd.gov/ /media/files/ab617-community-health/west-oakland/100219files/final-plan-vol-1-100219-pdf.pdf?la=en Retrieved December 13, 2021.

Park, S.S., Vijayan, A., Mara, S.L. and Herner, J.D., 2016. Investigating the real-world emission characteristics of light-duty gasoline vehicles and their relationship to local socioeconomic conditions in three communities in Los Angeles, California. Journal of the Air \& Waste Management Association, 66(10), pp.1031-1044., https://doi.org/10.1080/10962247.2016.1197166

Park, S.S., Kozawa, K., Fruin, S., Mara, S., Hsu, Y.K., Jakober, C., Winer, A. and Herner, J., 2011. Emission factors for high-emitting vehicles based on on-road measurements of individual vehicle exhaust with a mobile measurement platform. Journal of the Air \& Waste Management Association, 61(10), pp.1046-1056., https://doi.org/10.1080/10473289.2011.595981

Preble, C.V., Cados, T.E., Harley, R.A. and Kirchstetter, T.W., 2018. In-use performance and durability of particle filters on heavy-duty diesel trucks. Environmental science \& technology, 52(20), pp.11913-11921., https://doi.org/10.1021/acs.est.8b02977

Robinson, A.L., Grieshop, A.P., Donahue, N.M. and Hunt, S.W., 2010. Updating the conceptual model for fine particle mass 275 emissions from combustion systems Allen L. Robinson. Journal of the Air \& Waste Management Association, 60(10), pp.1204-1222., https://doi.org/10.3155/1047-3289.60.10.1204 
Shah, R.U., Robinson, E.S., Gu, P., Robinson, A.L., Apte, J.S. and Presto, A.A., 2018. High-spatial-resolution mapping and source apportionment of aerosol composition in Oakland, California, using mobile aerosol mass spectrometry. Atmospheric Chemistry and Physics, 18(22), pp.16325-16344., https://doi.org/10.5194/acp-18-16325-2018

Tessum, C.W., Apte, J.S., Goodkind, A.L., Muller, N.Z., Mullins, K.A., Paolella, D.A., Polasky, S., Springer, N.P., Thakrar, S.K., Marshall, J.D. and Hill, J.D., 2019. Inequity in consumption of goods and services adds to racial-ethnic disparities in air pollution exposure. Proceedings of the National Academy of Sciences, 116(13), pp.6001-6006., https://doi.org/10.1073/pnas.1818859116

Zimmerman, N., Presto, A.A., Kumar, S.P., Gu, J., Hauryliuk, A., Robinson, E.S., Robinson, A.L. and Subramanian, R., 2018. A machine learning calibration model using random forests to improve sensor performance for lower-cost air quality monitoring. Atmospheric Measurement Techniques, 11(1), pp.291-313., https://doi.org/10.5194/amt-11-291-2018

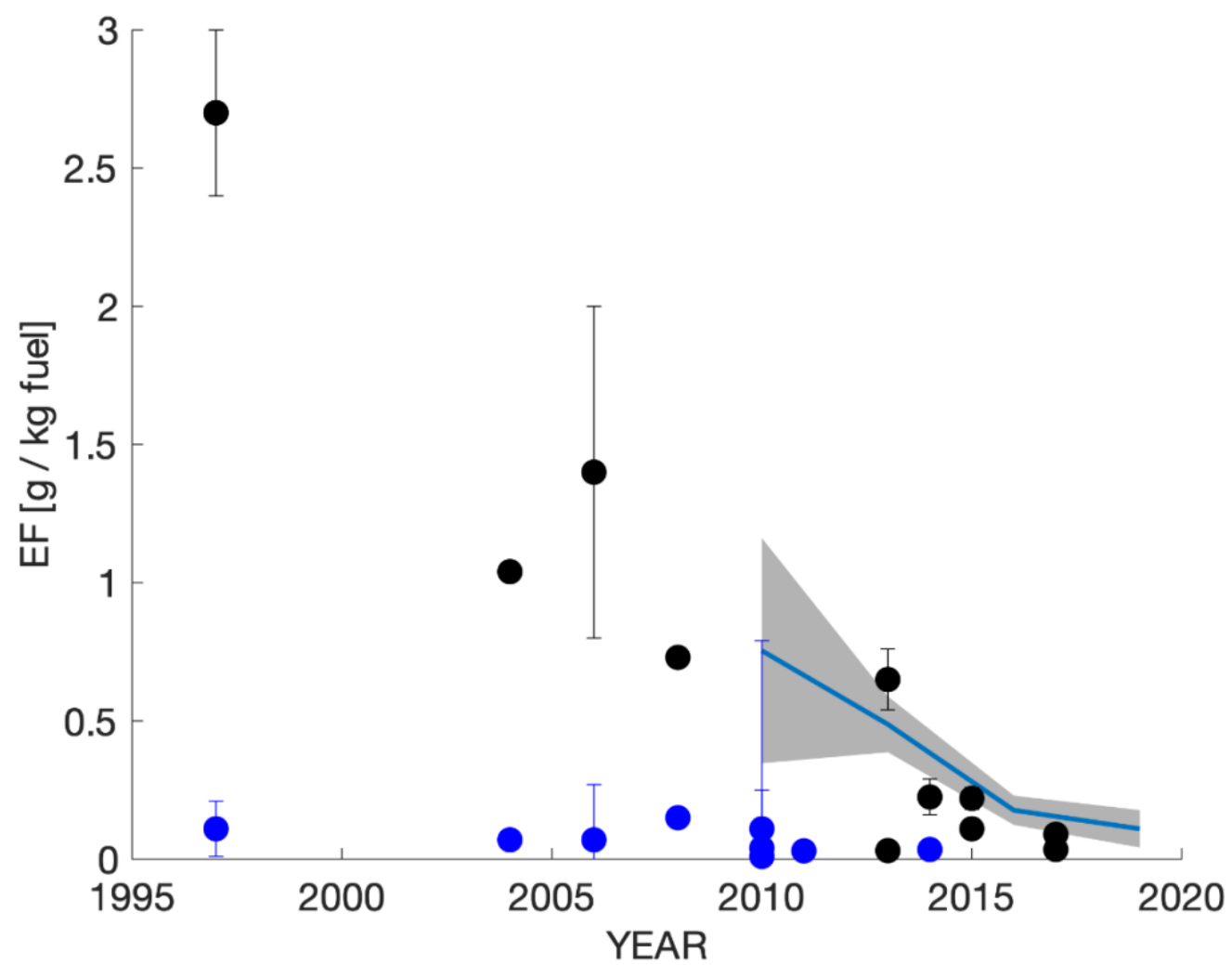

290 Figure 1: On-road measurements of emissions factors, from other studies. HDV (black) emissions factors converge on LDV (blue) emissions factors. Some studies do not give error bars. Grey patches and blue trendline indicate findings from this study for the two highway sites (RWC and SR) available during all three time periods. Patches span the mean and standard deviations of emissions factors from these two sites during each time period. 
https://doi.org/10.5194/acp-2021-1042

Preprint. Discussion started: 31 January 2022

(c) Author(s) 2022. CC BY 4.0 License.
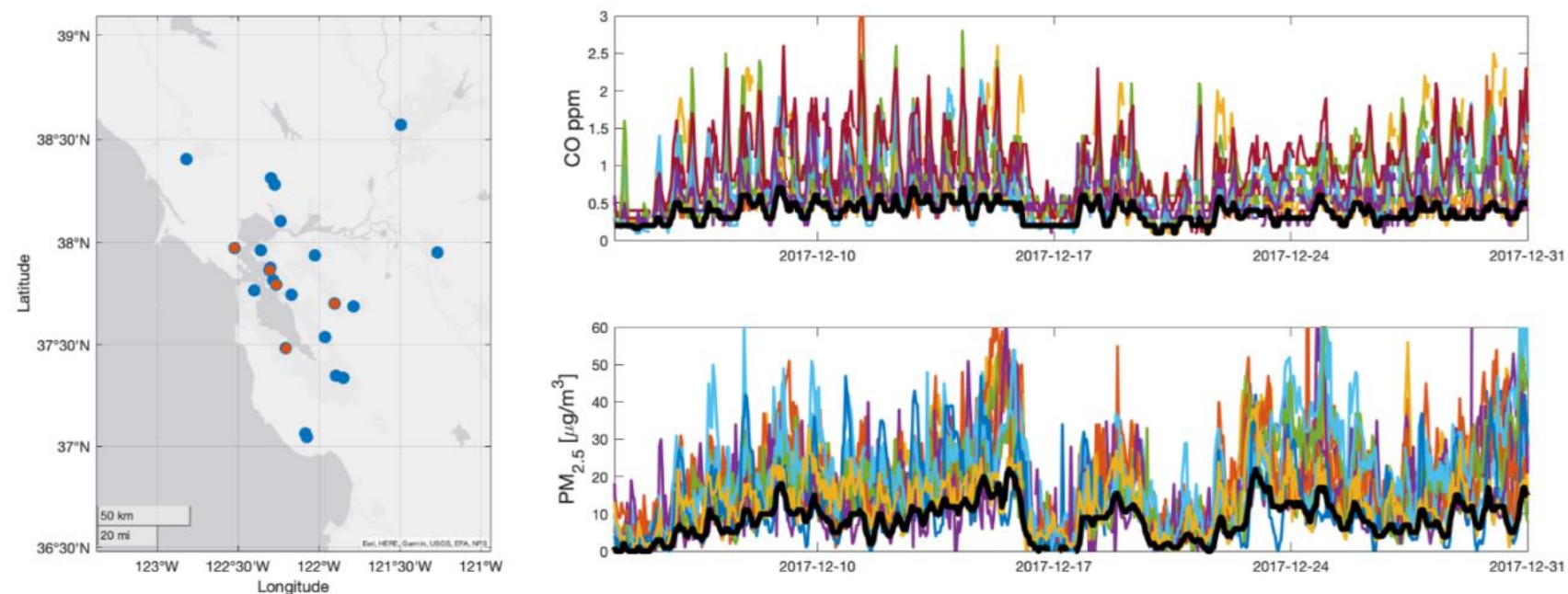

Figure 2 (Left): BAAQMD sites used in this study. Red dots show near-highway sites at which HDV emissions factors were determined. Blue sites were used only for determining regional signal. Figure 2 (Right). Aerosol and CO at each BAAQMD site (various colors). The regional background (black), is defined as the lowest $10^{\text {th }}$ percentile of all signals within a rolling 4-hour window. Figure credit: Esri, HERE, Garmin, USGS, EPA, NPS. 
https://doi.org/10.5194/acp-2021-1042

Preprint. Discussion started: 31 January 2022

(c) Author(s) 2022. CC BY 4.0 License.

(c) (i)

\section{Pleasanton 2018-2020}

10-12\% TRUCKS

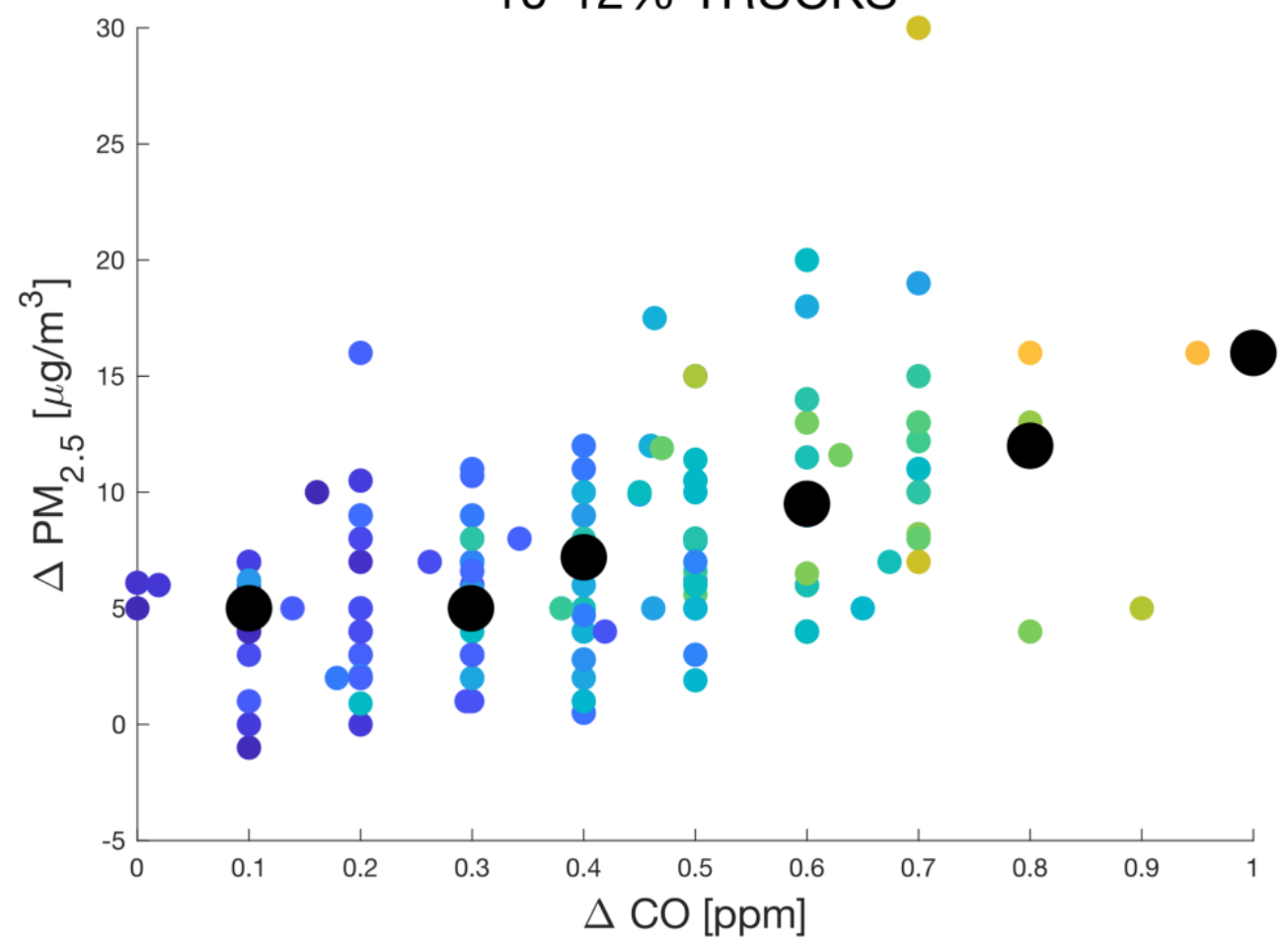

Figure 3. $\triangle \mathrm{PM}$ vs. $\triangle \mathrm{CO}$ at Pleasanton site during the $2018-2020$ time period for which $10-12 \%$ of traffic flow is trucks. Data is colored by

$\mathrm{NO}_{\mathrm{x}}$ concentration. Black point represent the median $\Delta \mathrm{PM}$ value falling within a $0.05 \mathrm{ppm}$ bin of $\Delta \mathrm{CO}$. These points are fit linearly to find slope, $\alpha$. 
https://doi.org/10.5194/acp-2021-1042

Preprint. Discussion started: 31 January 2022

(c) Author(s) 2022. CC BY 4.0 License.

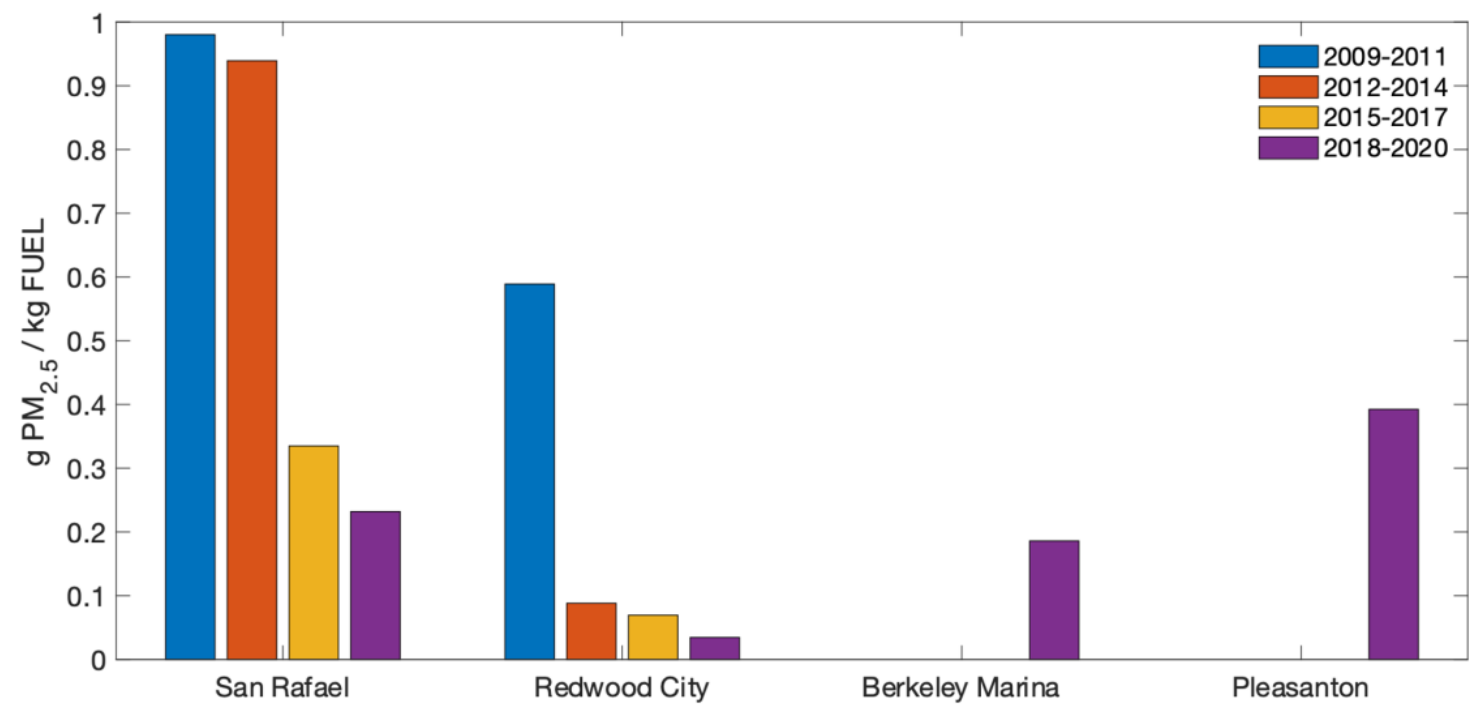

Figure 4: Top: Fleet emissions factors, derived from all sites, all years, binned by truck fraction. Bottom: HDV emissions factor at near highway sites during 2009-2011, 2012-2014, 2015-2017, and 2018-2020 time period. 
https://doi.org/10.5194/acp-2021-1042

Preprint. Discussion started: 31 January 2022

(C) Author(s) 2022. CC BY 4.0 License.

(c) (i)
Atmospheric

Chemistry

and Physics

Discussions

Study

Year of Measurements Vehicle Type

Measurement

Location

$E F_{C O}\left(g / k g\right.$ fuel) $\quad E F_{P M}(g / k g$ fuel $)$

\begin{tabular}{|c|c|c|c|c|c|}
\hline Kirchstetter (1999) & 1997 & Light Duty & $\begin{array}{l}\text { Caldecott Tunnel, } \\
\text { Oakland CA }\end{array}$ & & $0.11 \pm 0.1$ \\
\hline Kirchstetter (1999) & 1997 & Heavy Duty & $\begin{array}{l}\text { Caldecott Tunnel, } \\
\text { Oakland CA }\end{array}$ & & $2.7 \pm 0.3$ \\
\hline Geller (2005) & 2004 & Light Duty & $\begin{array}{l}\text { Caldecott Tunnel, } \\
\text { Oakland CA }\end{array}$ & & $0.07 \pm 0.02$ \\
\hline Geller (2005) & 2004 & Heavy Duty & $\begin{array}{l}\text { Caldecott Tunnel, } \\
\text { Oakland CA }\end{array}$ & & $1.04 \pm 0.02$ \\
\hline Ban-Weiss (2008) & 2006 & Light Duty & $\begin{array}{l}\text { Caldecott Tunnel, } \\
\text { Oakland CA }\end{array}$ & & $0.07 \pm 0.2$ \\
\hline Ban-Weiss (2008) & 2006 & Heavy Duty & $\begin{array}{l}\text { Caldecott Tunnel, } \\
\text { Oakland CA }\end{array}$ & & $1.4 \pm 0.6$ \\
\hline \multirow[t]{2}{*}{ Park (2011)* } & 2007 & Light Duty & $\begin{array}{l}\text { Los Angeles, CA } \\
\text { (Wilmington) }\end{array}$ & 47 & 0.15 \\
\hline & 2007 & Heavy Duty & $\begin{array}{l}\text { Los Angeles, CA } \\
\text { (Wilmington) }\end{array}$ & 36 & 0.73 \\
\hline Dallman (2012) & 2010 & Heavy Duty & $\begin{array}{l}\text { Caldecott Tunnel, } \\
\text { Oakland CA }\end{array}$ & $8.0 \pm 1.2$ & \\
\hline Dallman (2013) & 2010 & Light Duty & $\begin{array}{l}\text { Caldecott Tunnel, } \\
\text { Oakland CA }\end{array}$ & $14.3 \pm 0.7$ & $0.038 \pm 0.010$ \\
\hline Bishop (2015) & 2013 & Heavy Duty & Cottonwood, CA & & $0.65 \pm 0.11$ \\
\hline Bishop (2015) & 2013 & Heavy Duty & Port of Los Angeles & & $0.031 \pm 0.007$ \\
\hline \multirow[t]{3}{*}{ Park (2016) } & 2011 & Light Duty & West Hollywood & $15.2 \pm 53.8$ & $0.01 \pm 0.01$ \\
\hline & 2011 & Light Duty & Boyle Heights & $36.8 \pm 85.6$ & $0.11 \pm 0.68$ \\
\hline & 2011 & Light Duty & $\begin{array}{l}\text { Los Angeles, CA } \\
\text { (Wilmington) }\end{array}$ & $46.6 \pm 117.9$ & $0.04 \pm 0.21$ \\
\hline \multirow[t]{2}{*}{ Haugen (2017) } & 2015 & Heavy Duty & Port of Los Angeles & $1.6 \pm 0.4$ & $0.11 \pm 0.01$ \\
\hline & 2015 & Heavy Duty & Cottonwood, CA & $3.0 \pm 0.2$ & $0.22 \pm 0.04$ \\
\hline \multirow[t]{2}{*}{ Haugen (2018) } & 2017 & Heavy Duty & Port of Los Angeles & $1.7 \pm 0.3$ & $0.035 \pm 0.01$ \\
\hline & 2017 & Heavy Duty & Cottonwood, CA & $2.8 \pm 0.4$ & $0.09 \pm 0.005$ \\
\hline \multirow[t]{2}{*}{ Li (2018) } & 2014 & Light Duty & Pittsburgh, PA & & $0.035 \pm 0.008$ \\
\hline & 2014 & Heavy Duty & Pittsburgh, PA & & $0.225 \pm 0.065$ \\
\hline
\end{tabular}

* Note that in Park (2011), no error in emissions factors were reported.

Table 1: Summary of emission factors derived by previous studies. 